\title{
LI. On the conductibility of the earth for electricity
}

\section{James Napier Esq.}

To cite this article: James Napier Esq. (1850) LI. On the conductibility of the earth for electricity, Philosophical Magazine Series 3, 37:251, 390-391, DOI: $10.1080 / 14786445008646633$

To link to this article: http://dx.doi.org/10.1080/14786445008646633

曲 Published online: 30 Apr 2009.

Submit your article to this journal

Џ Article views: 3

Q View related articles $\sqsubset$ 


\title{
LI. On the Conductibility of the Earth for Electricity. By James Napien, Esq.*
}

\begin{abstract}
A $\mathrm{T}$ the recent meeting of the British Association in EdinA burgh, Professor Matteucci communicated a paper upon the conductibility of the earth, in which are given many interesting experiments; but it is there stated that hitherto "nothing had been known of the laws and theory of this singular phenomenon." I thought that the theory of the conductibility of the earth for electricity had been long known to men of science in this country, and the cause to be, as $\mathrm{Mr}$. R. Hunt stated at the conclusion of the paper, depending upon the water contained in the superficial stratum of the earth. In corroboration of Mr. Hunt's remarks, I send you the results of a few experiments made in 184.3 upon this subject, which were not published at the time, from the belief that the conclusions they led to were previously well known.
\end{abstract}

$\mathrm{My}$ object in these experiments was to apply the electricity obtained from the earth to the deposition of metals; the first experiments were, placing pieces of zinc and copper in the earth so as to constitute a battery; but I was soon struck with the fact that it did not appear of any consequence, as regards the quantity and power of the electric current, whether these metals were placed only a few inches apart or a number of feet, or yards, or acres, or whether there stood between them trees, houses, or streets; indeed many of the experiments were made by having one plate of metal imbedded in the garden in front and another in the garden behind my house, which had a sun's flat; and there was no apparent difference in the results obtained under these conditions to those obtained when both metals were imbedded a few inches apart in one garden. The question which suggested itself from these results was, whether this conducting power was dependent upon the nature of the materials composing the earth? To ascertain this, a plate of zinc and copper were laid upon a large table a few inches apart, and connected by a wire. When the table was wet there was a current passing, but not when dry; when these plates were imbedded in sawdust and in sand, a current was always obtained when these materials were wet, but ceased when they were dry. A large vessel was then filled with earth from the garden, and a zinc and copper plate imbedded in it, and the whole placed in such a cundition as to allow the earth to dry

* Communicated by the Author. 
slowly. It was interesting to remark during this experiment the gradual decline of the galvanometer needle, until the earth was perfectly dry, when it ceased to indicate any passing current. The earth was now made wet around, and in contact with the plates, leaving a portion of the earth between them dry. Under these conditions there was no current; but whenever the earth was all moistened between the plates, the current of electricity became as strong as at first. A common Wollaston's battery, charged with acid, having the two terminals or poles connected by the earth in the vessel, gave similar results; when the earth was dry there was no conduction; when wet, the current passed through easily. All these led to one conclusion, that the conducting medium was the water, which, if I mistake not, had been pointed out some time previous to my experiments, both by Mr. Hunt and Mr. Fox. And they are also the conclusions which Professor Matteucci has more recently come to.

Glasgow, 17th October, 1850.

\section{Notices respecting New Books.}

On the Strength of Materials ; containing various original and useful Formula, specially adapted to Tubular Bridges, Wrought Iron and Cast Iron Beams, \&c. By Thomas Tate, Author of the Principles of the Differential Calculus, Factorial Analysis, \&c. London: Longmans, 1850.

THIS work contains in ninety-six octavo pages the usual formulæ, besides those stated to be new, for computing the relative strength of beams of various forms. The notation appears to be well chosen, and the formulæ are neat, perspicuous, and convenient for use. Special attention has been given to the subject of hollow beams and tubular bridges; and the advantages of the cellular structure, angle irons, and other contrivances adopted in the great engineering works of the kind recently constructed, are duly set forth and explained. The book, we think, cannot fail to be appreciated by the practical engineer; though a few ta!)les showing the strength of the materials principally used in construction, and a somewhat greater variety of numerical examples, might possibly have rendered it more generally useful. 